This item was submitted to Loughborough's Research Repository by the author.

Items in Figshare are protected by copyright, with all rights reserved, unless otherwise indicated.

\title{
Continuities and discontinuities: issues concerning the establishment of a persistent sense of self amongst care leavers
}

PLEASE CITE THE PUBLISHED VERSION

http://dx.doi.org/10.1016/j.childyouth.2011.08.028

\section{PUBLISHER}

(C) Elsevier Ltd.

\section{VERSION}

AM (Accepted Manuscript)

\section{PUBLISHER STATEMENT}

This work is made available according to the conditions of the Creative Commons Attribution-NonCommercialNoDerivatives 4.0 International (CC BY-NC-ND 4.0) licence. Full details of this licence are available at: https://creativecommons.org/licenses/by-nc-nd/4.0/

\section{LICENCE}

CC BY-NC-ND 4.0

\section{REPOSITORY RECORD}

Ward, Harriet. 2019. "Continuities and Discontinuities: Issues Concerning the Establishment of a Persistent Sense of Self Amongst Care Leavers". figshare. https://hdl.handle.net/2134/15867. 
Continuities and discontinuities: issues concerning the establishment of a persistent sense of self amongst care leavers

Harriet Ward, Professor of Child and Family Research and Director, CCFR, Loughborough University

Email address: h.ward@lboro.ac.uk

Phone: $+44(0) 1509223672$

Mailing address: Centre for Child and Family Research, Department of Social Sciences, Loughborough University, Leicestershire, UK, LE11 3TU

Running title: Self continuity and care leavers

Address for reprints: as above 


\begin{abstract}
Research in a number of countries has demonstrated the importance of developing a sense of belonging and connectedness as key factors that facilitate the move towards independence for young people leaving care (see Stein, 2008). This paper utilises findings from a longitudinal study of looked after children (including interviews with care leavers) to explore how the evidence from Canadian research into the significance of perceptions of self continuity for identity formation can improve our understanding of care leavers' experiences and the factors that may act as barriers to their making a smooth transition.
\end{abstract}

The findings demonstrate the extent of disruption and instability that care leavers may experience both before, during and after the care episode. This lack of continuity is exemplified for many young people by the loss of treasured possessions such as mementoes of parents and photographs of previous homes and carers. Constant experience of transience may act as a barrier to the establishment of a sense of self continuity. This may increase the likelihood of leaving care becoming a transitional flashpoint during which difficulties in moving on to adulthood increase the propensity for young people to lose sight of the thread that connects their past to their future, and engage in self-destructive behaviours. Premature, compressed and accelerated transitions may increase the chances of this happening. The paper argues that greater attention to the preservation of possessions that have a symbolic value might be a simple means of helping care leavers develop a stronger sense of connectedness.

Key words: care leavers; care leavers: sense of identity; children in out of home care: discontinuities; children in out-of-home care: possessions;

\title{
1.1 Introduction
}

Research in Australia has shown that 'a sense of belonging and connectedness' is a key factor in facilitating the move towards independence for young people leaving care (see Cashmore and Mendes, 2008; Cashmore and Paxman, 1996; Maunders, Liddell, Liddell and Green, 1999). A German study shows that 'the ability to connect biographically developed patterns of actions' plays a central role in transitions from care to independence (see Köngeter, Schröer and Zeller, 2008; Finkel, 2004). Two papers in this Special Issue (Ibrahim and Howe, 2011 and Dima and Skehill,2011) explore the centrality of identity formation to the process of leaving care in two other very different societies, Jordan and Rumania. It is clear that this issue is fundamental to making a successful transition from care to adulthood in many different societies. This paper utilises findings from a longitudinal study of looked after children in England to 
explore how evidence from Canadian research into identity formation can improve our understanding of the challenges facing care leavers and the factors that can make it easier or more difficult to overcome them.

\subsection{Self-continuity and identity formation}

Chandler, Lalonde and colleagues' research on children's changing perceptions of self-continuity provides a valuable context for understanding the difficulties faced by some vulnerable groups in developing a strong sense of connectedness (see, for instance, Chandler, Boyes, Ball and Hala,1987); Chandler, Lalonde, Sokol and Hallett, 2003; Lalonde and Chandler, 2002; Lalonde, 2006). Their central thesis is that, in order to develop a robust sense of self, we must all learn to reconcile two seemingly contradictory factors: the need to change and develop alongside the need somehow also to remain the same:

on threat of otherwise ceasing to be recognisable as a self, all of us must satisfy at least two constitutive conditions. The first of these is that selves are obliged to keep moving or die, and, so, must continually change. The second is that selves must also somehow remain the same, lest all notions of moral responsibility and any commitment to an as yet unrealised future become nonsensical (Chandler, Lalonde, Sokol and Hallett, 2003, p.vi).

The authors' wide body of empirical research explores the extent to which young people do or do not perceive themselves and others as possessing a continuing self that in some way persists from birth to adulthood despite inevitable and extensive changes. Their findings have led to the conclusion that a key element of the identity formation process is 'acquiring a working sense of one's own personal persistence in time (... an understanding that, despite all the changes that life and time has in store, you can claim confident ownership of your own past and feel a strong commitment to your own future)' (Lalonde, 2006, p.56). Empirical research with different age groups has shown that:

as young persons themselves become more complex, so too do the arguments they offer up....Between the ages of 12 and $18 \ldots$, the average young person can be expected to step through a series of up to five different and increasingly complicated ways of warranting his or her own persistence in time (Lalonde, 2006, p.63). 
During adolescence, at a time when they may be negotiating numerous transformations of identity, young people may be at particular risk of losing this sense of self continuity. This is the time when they are most likely to encounter 'transitional moments' when they may have few resources for solving the perennial problem of sameness within change, and are 'at special risk of at least temporarily losing the continuity preserving thread that guarantees them a sufficient personal stake in the future' (Chandler et al, 2003, p.56). At these 'dislocated' moments:

neither their old nor their oncoming self-continuity warranting strategies may prove especially effective. As a consequence, their past and future prospects both risk collapsing back into the same specious present where nothing matters except the momentary pain...(Chandler et al, 2003, p55).

These are the times when the usual barriers are lowered and young people may engage in self destructive behaviours that show a lack of appropriate concern for their future well being.

Chandler, Lalonde and colleagues' research has focussed on the relationship between perceptions of self-continuity, commitment to a future and adolescent suicide; they have shown that a sense of both personal and cultural continuity are significant factors in the variations in suicide rates amongst First Nations young people in Canada. However their central thesis, that a sense of self-continuity is fundamental to successful identity formation, is relevant to many other vulnerable groups.

\subsection{Perceptions of self continuity within the context of leaving care}

The Canadian research has particular relevance to the experiences of children and young people in care, many of whose lives are characterised by multiple discontinuities which, we could hypothesise, would appear to be inimical to the establishment of a sense of self-persistence. These theories are of specific relevance to those young people preparing to make the transition from care to independence, for they may provide a conceptual basis for understanding the impact of past and present discontinuities on young people's attempts to 
develop a continuous, persistent sense of self that endures through a time of extensive change. The rest of this paper explores this argument further, focussing on data from a cohort of children and young people whose experiences of the English care system were tracked for three years.

\subsection{Outcomes for Looked After Children cohort}

The purpose of a series of studies on outcomes for looked after children was to explore how far the experiences encountered by children looked after away from home influence their psychosocial development (see Ward and Skuse, 2001; Skuse, Ward and Macdonald, 2001; Skuse and Ward, 2003; Ward, Munro and Dearden, 2006; Sempik, Ward and Darker 2008; Darker, Ward and Caulfield, 2008: Ward, 2009). The full cohort studied consisted of 242 children and young people who had been looked after for at least a year by one of six English local authorities; data concerning their needs, experiences and outcomes were collected from social work case files for a period of three years after entry to care. A subset of additional, more detailed, data was collected from case files and interviews with carers, professionals and birth parents concerning the needs and experiences of the 42 children in the sample who entered the care of the authorities before their first birthdays (Ward, Munro and Dearden, 2006; Ward and Munro, 2010). Extensive, qualitative data were collected through semi-structured interviews with a number of children and young people who left the care of the local authorities during the three years of the study.

\subsubsection{Interview subgroup}

Although 125 children and young people met the criteria for inclusion in the sub-group who were interviewed, there were substantial difficulties in tracing or gaining access or permission to speak to a high proportion of them; in the event 49 children and young people were interviewed, $39 \%$ of those who were eligible. 
Interviews were held at least fifteen months after children and young people had left the care of the local authorities; 25 (about 50\%) of them were interviewed on a second occasion, about a year after the first interview.

The Children (Leaving Care) Act 2000 (England and Wales) provides additional support over the transition period for those young people aged sixteen and over who have been looked after for a period of at least thirteen weeks since their fourteenth birthday'. Nineteen of those interviewed met these criteria and could thus be defined as 'care leavers'. However, many of the other children in the full cohort and in the interview subgroup had experiences that shed light on how care and their pre-care histories were likely to impact on the ability of care leavers to develop a continuous and persistent sense of self, and so evidence from the full qualitative and quantitative datasets is presented in this paper.

\subsubsection{Issues concerning the data}

Extensive data were collected on a large group of hard to access children in this study, and have provided a rich resource for subsequent policy development (Department of Health, 1999; Department of Health, 1999-2001, Department of Health, 2002; Department of Health and Department for Education and Employment, 2000; Department of Health, Department for Education and Employment and Home Office, 2000; Department for Education and Skills, 2003; Department for Education, 2010). Nevertheless, the full cohort was undoubtedly incomplete; the first interim report focussed on the difficulties the local authorities faced in identifying children who were eligible for inclusion in the sample (Ward and Skuse, 1999).

Notwithstanding the weaknesses in the dataset, there was no evidence of any particular bias in the full cohort in terms of age, gender or reason for admission. On the other hand, difficulties in accessing those children who had left the care of the authorities resulted in the subset who were interviewed being skewed (see Munro, Holmes and Ward 2006). Comparison with the case file data shows that this subgroup had, on average, better educational outcomes, fewer emotional and behavioural difficulties and fewer changes of care placements than the full cohort studied. As we shall see, the experiences 
of many of these young people illuminate numerous factors that are likely to impact negatively on the ability of care leavers to develop a strong sense of self continuity; it is probable that, had we been able to trace all the eligible young people, the data would have shown more evidence of this nature.

\subsection{Key findings}

\subsubsection{Discontinuities: homes}

The findings demonstrate the extent to which children and young people who become looked after by local authorities in England and Wales experience upheavals and discontinuities throughout their childhood and adolescence. Frequent changes of household, domicile and primary carer were common before entry to care, during the care episode and after departure.

Those infants who became looked after before their first birthdays had previously experienced repeated changes of address and primary carer while living with their birth families: eleven (28\%) of them had had four or more addresses in this short period (Ward, Munro and Dearden, 2006); these data are not available for other children in the cohort, but there is no reason to suppose that their experiences would have been less disruptive. The pattern continued after entry to care: in the 3.5 years post admission, over half the sample (142: 59\%) had three or more placements, and 53 (22\%) had six or more. In both the first and the second years of the children's care episodes, over half of all placements lasted for six months or less; it was not until the third year after entry that the average length of placements began to increase (see Ward, 2009). This level of instability in the care system is similar to that shown in other British studies (see Sinclair et al, 2007). Nevertheless, the interview data indicate that a number of children had experienced greater stability in care than while living with their birth families before admission.

The interviews also indicate that the pattern of discontinuity and disruption continued for many children and young people after they left the care of the authorities. Those older teenagers who returned from care to birth parents, often found that the longed for re-unification quickly turned sour as arrangements broke down and they had to move out of the family home: 
"I hoped that I would get on with my Mum and her boyfriend and that I would be able to go on holiday -' cause one year we all went on holiday together. But it only lasted about three days. We just didn't get on.

\section{Were you disappointed?}

Yes, because all I ever wanted was to be near my Mum and sisters ....'

(Christine. Age at entry: 13 years. Age left: 15 years old.)

Quantitative data from other studies substantiates the high levels of instability experienced by young people after they leave local authority care and confirms the evidence from these interviews that, in spite of high levels of placement change, many children experience greater stability in care than they do with their birth families (see Wade et al, forthcoming; Farmer and Lutman, 2009).

Those young people who left care for independent living followed a very similar pattern to those who returned to their birth families in that the majority of these arrangements also proved to be unstable. Indeed, some young people appeared to be establishing a pattern of transience, so that their lives in the community seemed to be a continuation of the instability of their lives whilst in the care of the local authority and, indeed, with their families before they were placed.

\subsubsection{Discontinuities: education}

The theme of disruption and discontinuity was also reflected in children and young people's education. The following case study demonstrates an educational history that was not untypical of some of the young people interviewed:

Gina attended one primary school between the ages of five and nine. Her family then moved house and she attended another school until she was ten. She then experienced a routine move to a middle school where she stayed until she was twelve. Her family then moved to another city and she attended a secondary school until she was thirteen. Her family moved house again, back to their hometown and Gina went back to her old middle school for a few months. Following another house move she had a period of two months where she had no school place. Eventually she was able to attend an upper school for a few months before her parents requested that she be moved to a girls' school. At thirteen Gina was enrolled at the girls' school but rarely attended. She was accommodated a year later at 
age fourteen. When she was fifteen she was offered a place at a college where she went for a few months until she dropped out.

(Gina: Age at entry to care: 14 years. Age left 16 years).

For many children there was evidence of more disruption to education before and after the care episode than during it.

\subsubsection{Discontinuities: relationships}

Moves between schools and placements were also accompanied by continuous changes within them. Not only did children and young people change social workers as they were moved from one part of the system to another, but friendship patterns constantly changed as they and the friends they made in care moved in and out of schools and placements. In residential units, staff working schedules further reinforced the experience of transience:

I felt like I was, it was just me against the world, kind of thing. Because I didn't have my family. And people like the carers, they were, they'd come and go, change every four days. You'd see one once every four days or something. So it was just me....

(Gina. Age at entry: 14 years. Age left: 16 years old).

There were also few indications of continuing relationships with substitute carers for those young people who had little contact or had become estranged from their birth families. Adolescents sometimes reported having been back to their residential units to visit staff, but most of these contacts had been fleeting and confined to the early months after leaving; others were still in contact with foster carers two or three years after leaving care, but further questions revealed that, while a handful were receiving extensive support as quasi members of the foster carer's family, this was rare. For most young people the relationship, like so many other experiences, had been short-lived and subsequent contact was confined to chance meetings on the streets or in the shops.

\subsubsection{Loss of belongings}

One feature of the multiple disruptions and discontinuities that characterised the lives of so many of these young people was the constant experience of 
loss, a point that was graphically demonstrated when they talked about their possessions.

With such frequent changes of environment, material possessions may become particularly important as they have the potential to offer one of the few points of consistency in lives that are characterised by transience. Nevertheless, during the course of the interviews a number of young people commented that belongings had gone missing during their time in care or accommodation. This happened so frequently that more focussed questions were asked about this issue in second interviews. Over half of the adolescents interviewed reported losing personal possessions as a significant feature of their care experience.

In some instances the loss of possessions simply appeared to provide yet another indication of instability and transience, a point vividly made by one young woman who reported that her former life had been so chaotic that she did not have anything to lose:

I never really had any....I mean what I left really was boxes, just boxes, mainly clothes but I never really had things. I mean, where I'd moved so much, even when I was a kid we moved quite a lot when I was little, ...Everything got lost somewhere along the line, so I never really had anything that I've kept through and through, so it's always been. Never got anything to keep really.

(Lisa. Age at entry: 15 years. Age left: 18 years old.)

However in other instances such losses had a more symbolic meaning. Some possessions are particularly precious for children who become looked after, representing what may be their only tangible reminder of their former lives and carers. Other children may use items from home as transitional objects to help them cope with the stress of change and instability, just as very young children often carry blankets or cuddly toys with them when going into strange situations. Indeed, Fahlberg (1994) noted that the retention of familiar objects serves as a useful mechanism for reducing the trauma associated with moving into care or changing placement. A number of these symbolic items, that provided a tangible link with the past, or proof of children's belonging to a particular family, were lost in the course of the care episode. For instance one young woman had stolen from her 'a gold chain I got when I was christened, 
from my godparents'. Another expressed the symbolic value of personal items that had gone missing:

'it's what your family's got you, that you've took with you, and then it's gone. So, and then, it's like now I see my mum and dad every day, but back then I didn't see them'

(Joanne. Age at entry: 14 years. Age left: 16 years old).

In other circumstances, however, possessions were deliberately withheld. When this happened their loss emphasised the extent to which a child or young person was excluded from, or denied membership of a particular family. Thus some birth families refused to allow children and young people to take cherished possessions with them when they entered care or accommodation:

'My family refused to give me anything belonging to my Dad or my TV or my toys, what I'd collected through the years. They basically said I didn't deserve them any more......And it didn't only happen once, it happened twice. When I first went into care from my step mum, she did the same, she wouldn't let me take my telly or anything in. And when I went to live my Nana, the stuff I'd got off my Nana, and the stuff, they wouldn't let me take neither'.

(Rob. Age at entry: 14 years. Age left: 18 years old.)

The only possessions this young man took with him into care were his clothes and a photograph of his father who had committed suicide when Rob was eleven. As his comments indicate, the withdrawal of the right to ownership could be used by adults to confirm that a child no longer belonged to the family.

The interviews showed that the denial of connectedness, expressed through the withdrawal of belongings, was a common theme, expressed both by birth families and by some foster carers when a relationship broke down. Some children and young people had, understandably, been upset that when a placement ended foster carers refused to allow them to keep presents they had previously given them:

'..she bought me a sheath knife, cos I went to scouts, and they used to do camp, she bought it for me, it had my name on the case....she bought it for me, it said my name on the back, so it's mine, she bought it for me and me alone and then when I were coming out, I never got my sheath knife back'

(Marcus. Age at entry: 9 years. Age left: 12 years old.) 
Others found they had not been allowed to retain tangible proof that they had once been part of a foster carer's family:

They (foster carers) took all my photos I had of them, so I've got no photos of them

(Lara: Age at entry: 15 years. Age left 17 years old).

\subsection{Discussion}

The children and young people in the care of local authorities in England and Wales are a heterogeneous population. Around $27 \%$ show no evidence of psychosocial problems, challenging behaviours or other additional needs; they tend to have relatively stable care histories and better welfare outcomes than other looked after children (see Ward and Holmes, 2008; Ward, Holmes and Soper, 2008). If these young people remain looked after until they approach adulthood, they are most likely to form a large part of the group who 'move on' successfully to independence. However there is considerable evidence that other care leavers have greater needs and more troubled life pathways; on approaching independence they may 'survive' with professional support and their own determination, or they may 'struggle' to cope at all (see Stein, 2008).

By all accounts the first months after leaving care can be the most difficult: in the words of one of the young people interviewed in the study presented above: 'nobody prepares you for the loneliness'. However, there is also harder evidence of increased mental health problems during this period. Dixon and colleagues (2006) found that, 12-15 months after leaving care, the percentage of young people self reporting mental health problems had doubled and $4 \%$ had attempted suicide. Saunders and Broad's earlier study had also found a high level of suicidal behaviour amongst care leavers, with nearly two thirds of their sample having considered suicide and $40 \%$ having attempted it on leaving care (Saunders and Broad, 1997). Almost half the adolescents in the study presented in this paper said that they had felt the need of psychotherapeutic support after they had left care.

These mental health outcomes are obviously a cause for concern. In part they may reflect the failure of the care system to address the consequences of children and young people's experiences of maltreatment before entry. Abuse 
and neglect are the primary reasons given for admission of $60 \%$ of children in the English care system (Department for Education, 2010); at entry to care, $72 \%$ of children and young people in the cohort discussed above showed the emotional and behavioural problems that are well recognised sequelae of these experiences (Sempik, Ward and Darker, 2008). Programmes to support looked after children in overcoming such problems are still in their infancy (Davies and Ward, forthcoming).

However, if the theories put forward by Chandler, Lalonde and colleagues are taken into account, then a further, significant factor may be involved. Making the transition from care to independence may prove to be one of the 'betwixt and between moments' when young people: 'find themselves between stages, which leaves them without a successful means of justifying their own continuity across time' (Chandler et al, 1987, p119). At such points a crisis of identity occurs, and suicidal or self-destructive behaviour becomes more likely.

There are two factors that may well increase the likelihood that leaving care becomes a flashpoint at which young people are at particular risk of losing their sense of self-continuity. The first is the process of making the transition to adulthood. During this time young people are required to adopt a series of different identities: from schoolchildren or students to members, or potential members, of the workforce; from being dependent members of a family to becoming independent adults responsible for looking after both themselves and their living arrangements; perhaps from being single to becoming a partner and/or a parent. It is now widely known that while their contemporaries are experiencing increasingly extended transitional periods, during which these identities are tried out sequentially, and sometimes temporarily rejected, care leavers experience compressed and accelerated transitions, during which they are sometimes required to adopt several new identities simultaneously, and with less chance of backtracking if they turn out not to be ready to adopt these new personae (see Stein, 2008). The early age at which some care leavers are still expected to cope with independence is also likely to exacerbate the pressures and increase the likelihood of challenges to their sense of self continuity. In spite of recent policy initiatives to support them for longer, 21\% of those who leave care in England are still only aged sixteen at the time (Department for Education, 2010); data on destinations are 
not available but we know that although not all sixteen year old care leavers are placed in independent living, other arrangements are often of very short duration (see Stein, Rees, Hicks and Gorin, 2009).

The empirical evidence presented in this paper introduces a third element that may well increase the risk of care leavers losing the thread of personal continuity as they face these challenges. This is their previous experience. We do not precisely know the impact of repeated changes of home, carers, school and friends on young people's ability to establish a sense of identity; research in this area, that explores further the Canadian model presented here, would be valuable. However it seems clear that young people whose life experience is characterised by transience and loss will have been required to adopt multiple changes of identity, and this may make it more difficult to retain a sense of their own continuity through time. Constant changes can hardly fail to reinforce the impression that nothing can be expected to endure, including a sense of self-persistence.

Within this context, the loss of treasured possessions is particularly significant. A wealth of anthropological research points to the symbolic value given to objects that provide a link with the past, particularly amongst people who have had to leave their homes. In an important paper, Parkin points out that when people become refugees:

Alongside the items to sell or use in defence en route, and the food, farming tools, mattresses, blankets, medicines, protective amulets, and children carried on shoulders or running alongside, are sometimes the compressed family photos, letters and personal effects of little or no utilitarian or market value (Parkin, 1999, p.313).

He argues that these apparently inessential items represent a link with a previous life, providing memories that 'can become an acceptably realistic link with the present, bridging the gap between past loss and future potential' (p315). They are necessary for 'perpetuating a personal and thence cultural identity', and their loss may represent 'a loss of self through material dispossession' (p.315). The loss of photographs or mementoes of home or previous carers must bear a similar significance for looked after children, particularly if other links with the past are tenuous. 
Moreover the manner in which belongings are sometimes withdrawn by birth families and carers, apparently in order to emphasise that a child no longer belongs in a particular family, must also chip away at an already fragile sense of identity and reinforce this sense of loss of self. Such actions must call into question a young person's understanding of their personal history, and make it harder, at particular flashpoints, to retain the sense of there being a continuous thread, linking the past to the present and the future.

\subsection{Conclusion: implications for policy and practice}

In this paper, the programme of research on identity formation undertaken by Chandler, Lalonde and colleagues, has provided a conceptual framework for understanding the likely impact of past experience of discontinuities and disruptions on the process of leaving care. I have argued that young people may show a greater propensity to adverse outcomes such as mental health problems, attempted or actual suicide and destructive behaviour patterns if their previous experience of discontinuity and dispossession has weakened their ownership of their past and their commitment to the future. The likelihood is particularly great if the transition to adulthood is premature, compressed and accelerated. It may then become a 'betwixt and between moment', when additional stresses caused by the simultaneous adoption of numerous new identities may lead young people to lose their sense of self continuity and become engaged in self-destructive behaviours that show little concern for their future well being.

If such a theoretical analysis proves to have practical validity there are obvious implications for policy and practice. The evidence adds further weight to policies aimed at reducing the number of care leavers who are moved into independence as soon as legally permissible; to those aimed at modelling the transition period more closely on the protracted and sequential experiences of the wider population; and to those that seek to ensure that care leavers have adequate emotional, as well as financial, support through an extended transition period. It also supports policy and practice that attempts both to reduce the amount of instability experienced by children and young people who enter or leave care, and preserve continuity of education and positive 
contact with family and friends that might serve to mitigate some of the impact of disruptions. Perhaps most significantly, the findings point to one relatively simple initiative that could be introduced to strengthen children's sense of a persistent and positive thread of identity that links their past to their present and future. Efforts should be made to promote greater understanding by carers and professionals of the symbolic value of possessions brought from home or presented as gifts that indicate that a child belongs to a particular family; making arrangements to ensure that these are properly valued and carefully preserved could promote the development of a stronger, more resilient sense of self continuity.

Acknowledgements:

This study was funded by the Department of Health and the Department for Children, Schools and Families, England.

\section{References}

Cashmore, J. \& Mendes, P. (2008). Australia. In Stein, M. and Munro, E.R. (eds) Young People's Transitions from Care to Adulthood: International Perspectives. London: Jessica Kingsley Publishers, pp 23-35.

Cashmore, J. \& Paxman, (1996) Longitudinal Study of Wards Leaving Care. Sydney: Department of Community Services and Social Policy Research Centre.

Chandler, M., Boyes, M., Ball, L. \& Hala, S. (1987). The conservation of selfhood: a developmental analysis of children's changing conceptions of self-continuity. In T. Honess \& K. Yardley (eds) Self and Identity: Perspectives across the Lifespan. London: Routledge and Kegan Paul. (pp108-120)

Chandler, M., Lalonde, C., Sokol, B. And Hallett, D. (2003) Personal Persistence, identity Development and Suicide: A Study of Native and Non-Native North American Adolescents. Monographs of the Society for Research in Child Development, Serial No.273 : 68 (2). 
Department for Education and Skills (2003). Every Child Matters Green paper: Cm5860. London: The Stationery Office

Darker, I., Ward, H. \& Caulfield, L. (2008). An analysis of offending in young people looked after by local authorities. Youth Justice, 8 (2), 134-148.

Davies, C., \& Ward, H. (Forthcoming). Safeguarding Children Across Services: Messages from Research on Identifying and Responding to Child Maltreatment. London: Jessica Kingsley Publishers.

Department for Children, Schools and Families. (2010) The Children Act 1989 Guidance and Regulations Volume 2: Care Planning, Placement and Case Review. London: Department for Children, Schools and Families

Department for Education (2010). Children Looked After by Local Authorities in England (including adoption and care leavers) - year ending 31 March 2010. London: Department for Education.

Department of Health (1999). Government Objectives for Children's Social Services. London: Department of Health.

Department of Health (1999-2001). Core Information Requirements for Children's Services (Data Model). London: Department of Health.

Department of Health (2002). Promoting the Health of Looked After Children. London: Department of Health.

Department of Health and the Department for Education and Employment (2000). Guidance on the Education of Children and Young People in Public Care. London: Department of Health and the Department for Education and Employment 
Department of Health, Department for Education and Employment and Home Office (2000). Framework for the Assessment of Children in Need and their Families. London: The Stationery Office.

Department of Health and National Assembly for Wales (2001-3). The Integrated Children's System: Guidance on the Adoption and Children Act, 2002. London: Department of Health and National Assembly for Wales.

Dima, G. \& Skehill, C. (2011 this issue). Making sense of leaving care: a new framework for understanding care leavers' transition to independent living. Children and Youth Services Review

Dixon, J., Wade, J., Byford, S., Weatherly, H., \& Lee, J. (2006). Young People Leaving Care: A Study of Costs and Outcomes. Report to the DfES. SWRDU University of York, York.

Fahlberg, V. (1994). A Child's Journey Through Placement: UK Edition. London: BAAF.

Farmer, E., \& Lutman, E. (2009). Case Management and Outcomes for Neglected Children Returned to their Parents; a five year follow up study. Unpublished. Bristol: Bristol University.

Finkel, M. (2004) Selbständigkeit und etwas Glück. Einflüsse öffentlicher Erziehung auf die Perspektive Junger Frauen. Weinheim/ Munchen: Juventa

Ibrahim, R.W., \& Howe, D. (2011). The Experience of Jordanian Care Leavers making the Transition from Residential Care to Adulthood: The Influence of a Patriarchal and Collectivist Culture. Columbia University Middle East Research Center, Amman, Jordan and University of East Anglia, Norwich, UK.

Köngeter, S., Schröer, W., \& Zeller, M. (2008). Germany. In M. Stein, M. and E. R. Munro (eds) Young People's Transitions from Care to Adulthood: International Perspectives, London: Jessica Kingsley Publishers, pp 64-78. 
Lalonde, C. (2006) Identity formation and cultural resilience in Aboriginal communities. In R. J. Flynn, P. Dudding and J. G. Barber (eds) Promoting Resilience in Child Welfare. Ottawa: University of Ottawa Press, pp 52-71.

Lalonde, C. \& Chandler, M. (2002) Children's understanding of interpretation. New Ideas in Psychology, 20, 163-198

Maunders, D., Liddell, M., Liddell, M., \& Green, S. (1999). Young People Leaving Care and Protection: A Report to the National Youth Affairs Research Scheme. Hobart: Australian Clearing House for Youth Studies.

Munro, E., Holmes, L., \& Ward, H. (2006). Researching vulnerable groups: Ethical issues and the effective conduct of research in local authorities. British Journal of Social Work, 35 (7), 1023-1038.

Parkin, D. J. (1999) Mementoes as transitional objects in human displacement. Journal of Material Culture, 4, 303-320

Saunders, L., \& Broad, B. (1997). The Health Needs of Young People Leaving Care. Leicester: De Montfort University.

Sempik, J. Ward, H., and Darker, I. (2008). Emotional and behavioural difficulties of children and young people at entry into care. Clinical Child Psychology and Psychiatry, 13 (2) 221233.

Sinclair, I., Baker, C., Lee, J., \& Gibbs, I. (2007). The Pursuit of Permanence: A Study of the English Child Care System. London: Jessica Kingsley Publishers.

Skuse, T., Macdonald, I., \& Ward, H. (2001). Outcomes for Looked After Children: Third interim report to the Department of Health on Looking After Children: Transforming Data into Management Information. Loughborough: Centre for Child and Family Research. 
Skuse, T., \& Ward, H. (2003). Outcomes for Looked After Children: Children's Views, the Importance of Listening. An interim report to the Department of Health. Loughborough: Centre for Child and Family Research.

Stein, M. (2008). Transitions from Care to Adulthood: Messages from Research for Policy and Practice. In M. Stein and E. R. Munro (Eds.), Young People's Transitions from Care to Adulthood: International Research and Practice. London: Jessica Kingsley.

Stein, M., Rees, G., Hicks, L., \& Gorin, S. (2009). Neglected Adolescents: A Review of the Research. Unpublished literature review report. York: University of York.

Wade, J., Biehal, N., Farrelly, N., \& Sinclair, I. (Forthcoming). Caring for Abused and Neglected Children: Making the Right Decisions for Reunification or Long-Term Care. London: Jessica Kingsley Publishers.

Ward, H. (2009). Patterns of instability: moves within the English care system: their reasons, contexts and consequences. Child and Youth Services Review, 31, pp 1113-1118.

Ward, H., \& Holmes, L. (2008). Calculating the costs of local authority care for children with contrasting needs. Child and Family Social Work, 13 (1), pp 80-90.

Ward, H., Holmes, L., \& Soper, J. (2008). Costs and Consequences of Placing Children in Care, London: Jessica Kingsley Publishers.

Ward, H., \& Munro, E. (2010). Very young children in care in England: Issues for foster care. In Fernandez, E. and Barth, R. (eds) How does foster care work? International evidence of outcomes. London: Jessica Kingsley Publishers.

Ward, H., Munro, E.R., \& Dearden, C. (2006). Babies and Young Children in Care: Life Pathways, Decision-making and Practice. London: Jessica Kingsley Publishers. 
Ward, H., \& Skuse T. (1999). Looking After Children: Using data as management information. Report from First Year of Data Collection. Report to Department of Health. Totnes: Dartington Social Research Unit.

Ward, H., \& Skuse, T. (2001) Performance targets and stability of placements for children long looked after away from home. Children and Society, 15, pp1-14.

Ward, H., \& Skuse, T. (1999). Transforming Data into Management Information: Report to Department of Health on the first year of data collection. Second Interim Report. Loughborough: Loughborough University. 